\title{
Research on Supply Chain Coordination of TPL Supplier Participation*
}

\author{
Yun Liang ${ }^{1}$, Xiaode Zuo ${ }^{2}$, Hong Lei $^{2}$ \\ ${ }^{1}$ Business Administration Department, Gangdong University of Finance, Guangzhou, China; ${ }^{2}$ Management School of Jinan Univer- \\ sity, Guangzhou, China. \\ Email: liangy5@163.com,tzuoxd@jnu.edu.cn, leihong77@yahoo.com.cn
}

Received October $8^{\text {th }}, 2010$; revised November $9^{\text {th }}, 2010$; accepted November $14^{\text {th }}, 2010$.

\begin{abstract}
This paper used the Game Theory to research how to coordinate a kind of supply chain, which is made up of a dominant manufacturer, a TPL supplier and some retailers. It also discussed the node enterprises' decision models in three situations: no coordination, partly coordination and all coordination based on symmetric information and proved system's profit was optimal in the situation of all coordination. And then some ways of profit distribution were laid out. Finally, verified the validity of the models and ways of profit distribution through examples.
\end{abstract}

\section{Keywords: Supply Chain Coordination, Third Party Logistics, Profit Distribution}

\section{Introduction}

Enterprises tend to enhance their core competence through outsourcing logistics service under the fierce market condition. The demand for third party logistics, TPL for short, has growing gradually, so people pay more attention to the relationship between TPL providers and TPL demanders. Aidan. Reference [1] established a logistics service pricing model, which optimized the profits of both parties in a simple supply chain based on the assumption of linear demand. Reference [2] compared the pricing and profit conditions of TPL provider and demander before and after cooperation. Reference [3] analyzed some horizontal methods of the two parties used to coordinate the conflicts and contradictions in the outsourcing process. Reference [4] used game theory to study the coordination problem in a supply chain composed of a manufacturer, a TPL provider and a retailer. Reference [5] designed a TPL revenue sharing contract, and proved that this contract can form a sound internal incentive mechanism through a dynamic game approach.

It can be found that, current research mainly focus on the coordination issue between TPL provider and a single TPL demander. Little has done on the game relationship and coordination mechanism among the TPL provider, upstream and downstream enterprises. Also the condition

*This paper is funded by the 211 Engineering Program of Jinan University, Pre-Funded-Research of Management School. of more than one retailer and partial cooperation has seldom been paid attention to.

\section{Model Description}

Gong Deyan [6] established a supply chain model with a manufacturer, a retailer and a TPL provider. The difference between this paper to his is that, more than one retailer was considered, and the situation of partial cooperation was discussed, which makes the analysis more practical and can obtain more new conclusions. Node enterprises operated themselves as follows: first, the manufacturer selected a profit-optimizing wholesale price, $p_{m}$; retailer selected a service price $p_{l}$, which can maximize his own profit based on the given wholesale price; finally, retailer $i$ decided his optimal $p_{i}$ and order quantity $q_{i} . p_{l}$ was shared by the manufacturer and TPL together, and the sharing ratios are $\theta_{1}$, $\theta_{2}$ respectively. The costs of manufacturer, TPL and retailer are $c_{m}, c_{l}, c_{r}$.

The following assumptions were made:

Assumption 1: Information was perfectly symmetrical through the whole supply chain.

Assumption 2: All supply chain members were risk-neutral, and they were to maximize their own profits.

Assumption 3: The market demand is a linear function of the retailer price, that is, $p=a-b Q$, and $a, b$ were constants, $a>0, b>0$. 
Assumption 4: The unit cost and wholesale price for each retailer are the same.

Assumption 5: The manufacturer's capacity and TPL's ability were large enough to satisfy all demands..

\section{Set up and Solve the Model}

\subsection{Decentralized Model}

The manufacturer, TPL provider and retailers made their own decisions separately, that is, no alignment has been formed. So the Stackelberg model is:

$$
\begin{gathered}
\max \pi_{m}\left(p_{m}\right)=\left(p_{m}-c_{m}-\theta_{1} p_{l}\right) Q \\
\text { s.t. } \max \pi_{l}\left(p_{l}\right)=\left(p_{l}-c_{l}\right) Q \\
\text { s.t. } \max \pi_{r i}\left(p_{i}\right)=\left(p_{i}-c_{r}-p_{m}-\theta_{2} p_{l}\right) q_{i}
\end{gathered}
$$

Adopt the reverse inductive method, all the members' price decision can be solved as followed:

Phase 1, retailer $i$ will optimize his profit on a given $p_{l}$, which is

$$
\begin{aligned}
\max \pi_{r i}\left(p_{i}\right) & =\left(p_{i}-c_{r}-p_{m}-\theta_{2} p_{l}\right) q_{i} \\
& =\left(a-b Q-c_{r l}-p_{m-} \theta_{2} p_{l}\right) q_{i}
\end{aligned}
$$

Suppose $Q=q_{i}+Q_{j}$, we can get,

$$
\begin{gathered}
\max \pi_{r i}\left(p_{i}\right)=\left(a-b q_{i} Q_{j}-c_{r l}-p_{m-} \theta_{2} p_{l}\right) q_{i}, \\
\frac{\partial \pi_{r i}}{\partial q_{i}}=-2 b q_{i}-b Q_{j}+a-c_{r l}-p_{m-} \theta_{2} p_{l}
\end{gathered}
$$

Because $Q=n q, Q_{j}=Q-q_{i}=n q_{i}-q_{i}$

Therefore, $\frac{\partial \pi_{r i}}{\partial q_{i}}=-2 b(n+1) q_{i}+a-c_{r l}-p_{m-} \theta_{2} p_{l}$

Let it equals 0 , it can be solved that,

$$
\begin{aligned}
& q_{i}=\frac{a-c_{r l}-p_{m-} \theta_{2} p_{l}}{b(n+1)} \text { So, } \\
& Q=n q_{i}=\frac{n\left(a-c_{r l}-p_{m-} \theta_{2} p_{l}\right)}{b(n+1)}
\end{aligned}
$$

Phase 2, TPL provider will optimize his profit at a given $p_{m}$,

$$
\max \pi_{l}\left(p_{l}\right)=\left(p_{l}-c_{l}\right) Q
$$

Substitute the value of $Q$, we can get,

$$
p_{l}=\frac{a+\theta_{2} c_{l}-c_{r i}-p_{m}}{2 \theta_{2}}
$$

Phase 3, the manufacturer optimizes his profit,

$$
\max \pi_{m}\left(p_{m}\right)=\left(p_{m}-c_{m}-\theta_{1} p_{l}\right) Q
$$

Substitute the value of $Q$ and $p_{l}$, the optimal $p_{m}$, $p_{m}^{*}$ is arrived.

$$
p_{m}^{*}=\frac{a+\theta_{2} c_{m}-\theta_{2}^{2} c_{l}-c_{r i}}{\theta_{2}+1}
$$

Then we can get the optimal $p_{l}^{*}$ and $p_{i}^{*}$ :

$p_{l}^{*}=\frac{a+\left(2 \theta_{2}+1\right) c_{l}-c_{r}-c_{m}}{2\left(\theta_{2}+1\right)}, \quad p_{i}^{*}=a-\frac{n \theta_{2} R}{2(n+1)\left(\theta_{2}+1\right)}$

The total order quantity of all retailers is:

$$
Q^{*}=\frac{n \theta_{2} R}{2 b(n+1)\left(\theta_{2}+1\right)}
$$

So the profit of each supplier is:

$$
\begin{gathered}
\pi_{m}^{*}=\frac{n \theta_{2} R^{2}}{4 b(n+1)\left(\theta_{2}+1\right)}, \pi_{l}^{*}=\frac{n \theta_{2} R^{2}}{4 b(n+1)\left(\theta_{2}+1\right)^{2}}, \\
\pi_{r i}^{*}=\frac{\theta_{2}^{2} R^{2}}{4 b(n+1)^{2}\left(\theta_{2}+1\right)^{2}}
\end{gathered}
$$

The profit of the whole supply chain is:

$$
\pi_{s c}^{*}=\pi_{m}^{*}+\pi_{l}^{*}+\pi_{r}^{*}=\frac{\left(n^{2}+n+1\right) \theta_{2}^{2}+\left(2 n^{2}+2 n\right) \theta_{2}}{4 b(n+1)^{2}\left(\theta_{2}+1\right)^{2}} R^{2}
$$

Here, $R=a-c_{r}-c_{m}-c_{l}>0$

\subsection{Centralized Model}

Ye Fei and Li Yina [7] discussed the cooperation problem of a type of three-echelon supply chain with a manufacturer, a wholesaler and a retailer. Consider the partial cooperation in their paper, the following forms of alliances can be induced.

1) The manufacturer and TPL provider form a small scale alliance, and the retailers are not included. So the Stackelberg model should be:

$$
\begin{gathered}
\max \left(\pi_{m}+\pi_{l}\right)\left(p_{m}, p_{l}\right)=\left(p_{m}-c_{m}-c_{l}+\theta_{2} p_{l}\right) Q \\
\text { s.t.max } \pi_{r i}\left(p_{i}\right)=\left(p_{i}-c_{r}-p_{m}-\theta_{2} p_{l}\right) q_{i}
\end{gathered}
$$

Solve the model with reverse inductive method,

$$
\begin{gathered}
Q^{* *}=\frac{n R}{2 b(n+1)}, \quad p_{i}^{* *}=a-\frac{n R}{2(n+1)} \\
\left(\pi_{m}+\pi_{l}\right)^{* *}=\frac{n R^{2}}{4 b(n+1)}, \quad \pi_{r i}^{* *}=\frac{R^{2}}{4 b(n+1)^{2}}, \\
\pi_{s c}^{* *}=\frac{\left(n^{2}+2 n\right)}{4 b(n+1)^{2}} R^{2}
\end{gathered}
$$

2) TPL and retailers form a small scale alliance, and the manufacturer is not included. Now the Stackelberg model is:

$$
\max \pi_{m}\left(p_{m}\right)=\left(p_{m}-c_{m}-\theta_{1} p_{l}\right) Q
$$


s.t. $\max \left(\pi_{l}+\pi_{r}\right)\left(p_{l}, p_{i}\right)=\left(p_{i}-c_{r}-c_{l}-p_{m}+\theta_{1} p_{l}\right) Q$

Solve the model, we can get: $Q^{* * *}=\frac{R}{4 b}, p_{i}^{* * *}=a-\frac{R}{4}$, $\pi_{m}^{* * *}=\frac{R^{2}}{8 b},\left(\pi_{l}+\pi_{r}\right)^{* * *}=\frac{R^{2}}{16 b}, \quad \pi_{s c}^{* * *}=\frac{3 R^{2}}{16 b}$

3) The manufacturer and retailers form a small scale alliance, and TPL provider is not included. The Stackelberg model is:

$$
\begin{gathered}
\max \left(\pi_{m}+\pi_{r}\right)=\left(p_{i}-c_{r}-c_{m}-p_{l}\right) Q \\
\text { s.t. } \max \pi_{l}\left(p_{l}\right)=\left(p_{l}-c_{l}\right) Q
\end{gathered}
$$

Solve the model,

$$
\begin{gathered}
Q^{* * * *}=\frac{R}{4 b}, \quad p^{* * * *}=a-\frac{R}{4}, \pi_{l}^{* * * *}=\frac{R^{2}}{8 b}, \\
\left(\pi_{m}+\pi_{r}\right)^{* * * *}=\frac{R^{2}}{16 b}, \pi_{s c}^{* * * *}=\frac{3 R^{2}}{16 b}
\end{gathered}
$$

4) The manufacturer, TPL provider and retailers form a large scale alliance and make decisions together, so the profit function of the alliance is:

$$
\left(\pi_{m}+\pi_{l}+\pi_{r i}\right)\left(p_{i}\right)=\left(p_{i}-c_{m}-c_{l}-c_{r}\right) Q
$$

Solve the function, $Q^{* * * * *}=\frac{R}{2 b}$,

$$
p_{i}^{* * * * *}=\frac{a+c_{m}+c_{l}+c_{r}}{2}, \pi_{s c}^{* * * * *}=\frac{R^{2}}{4 b}
$$

\subsection{Model Analysis}

Conclusion 1: In the decentralized model, with the increase of $\theta_{2}$, the retailer price decreases, the sales volume increases, and the profits of the manufacturer, retailer, TPL provider and the whole supply chain increases. Their profits reach the peak when $\theta_{2}=1$.

Prove: from

$$
p_{i}^{*}=a-\frac{n \theta_{2} R}{2(n+1)\left(\theta_{2}+1\right)}=a-\frac{n R}{2(n+1)\left(1+\frac{1}{\theta_{2}}\right)},
$$

it is found that $p_{i}^{*}$ is an decreasing function of $\theta_{2}$.

$$
\text { From } Q^{*}=\frac{n \theta_{2} R}{2 b(n+1)\left(\theta_{2}+1\right)}=\frac{n R}{2 b(n+1)\left(1+\frac{1}{\theta_{2}}\right)} \text {, we }
$$

know $Q^{*}$ is an increasing function of $\theta_{2}$.

And

$$
\pi_{m}^{*}=\frac{n R^{2}}{4 b(n+1)\left(1+\frac{1}{\theta_{2}}\right)}, \quad \pi_{1}^{*}=\frac{n R^{2}}{4 b(n+1)\left(\theta_{2}+\frac{1}{\theta_{2}}+1\right)},
$$

$$
\pi_{r i}^{*}=\frac{n R^{2}}{4 b(n+1)^{2}\left(1+\frac{1}{\theta_{2}}\right)^{2}}
$$

Because $\theta_{2} \leq 1, \pi_{m}, \pi_{l}, \pi_{r i}$ are increasing functions of $\theta_{2}$, and from $\pi_{s c}=\pi_{m}+\pi_{l}+\pi_{r}$, so $\pi_{s c}$ is an increasing function of $\theta_{2}$ too. And when $\theta_{2}=1, \pi_{m}$, $\pi_{l}, \pi_{r i}, \pi_{s c}$ reach their peak value.

Conclusion 1 explains that, when outsourcing logistics service to TPL, the manufacturer burdens a low fee rate $\theta_{1}$, that lowers his wholesale price, which in turn to reduce the retail price and increase the sales volume (decreasing rate of retail price is smaller than the increasing rate of sales volume), and finally all parts' profit are improved. Therefore, the supply chain can get a Pareto improvement through rational sharing of logistics fee between the retailers and manufacturer.

Conclusion 2: In decentralized model, along with the increase of $n$, retailers' retail price and order quantity will increase, the profits of the manufacturer and TPL provider will increase, but retailer's profit will decrease.

Proof: from

$$
p_{i}^{*}=a-\frac{n \theta_{2} R}{2(n+1)\left(\theta_{2}+1\right)}=a-\frac{\theta_{2} R}{2\left(1+\frac{1}{n}\right)\left(\theta_{2}+1\right)}, \text { it is easy }
$$

to find out that $p_{i}^{*}$ is a decreasing function of $n$.

$$
\text { From } Q^{*}=\frac{n \theta_{2} R}{2 b(n+1)\left(\theta_{2}+1\right)}=\frac{\theta_{2} R}{2 b\left(1+\frac{1}{n}\right)\left(\theta_{2}+1\right)} \text {, we }
$$

know $Q^{*}$ is a increasing function of $n$.

$$
\begin{aligned}
& \text { From } \pi_{m}^{*}=\frac{\theta_{2} R^{2}}{4 b\left(1+\frac{1}{n}\right)\left(\theta_{2}+1\right)}, \\
& \pi_{l}^{*}=\frac{\theta_{2} R^{2}}{4 b\left(1+\frac{1}{n}\right)\left(\theta_{2}+1\right)^{2}}, \quad \pi_{r i}^{*}=\frac{\theta_{2}^{2} R^{2}}{4 b(n+1)^{2}\left(\theta_{2}+1\right)^{2}}, \text { It }
\end{aligned}
$$

can be found that $\pi_{m}, \pi_{l}$ are increasing functions of $n$ but $\pi_{r i}$ is decreasing function of $n$.

Conclusion 2 tells that, the manufacturer will choose more retailers to lower the retailer price, thus to increase the sales volume and enhance his own profit; however, the retailer expects fewer competitors, thus he can increase his profit by raising retail price.

Conclusion 3: In the centralized model, when the three form a big alliance, the whole supply chain's profit reaches the highest point and vise versa. In types of cooperation relationship, supply chain's profit is maximized in the manufacturer- TPL case. That is, $\pi_{s c}^{*}<\pi_{s c}^{* * *}=\pi_{s c}^{* * * *} \leq \pi_{s c}^{* *}<\pi_{s c}^{* * * * *}$

Proof: 


$$
\pi_{s c}^{*}-\pi_{s c}^{* * *}=\left[\left(n^{2}+2 n-3\right) \theta_{2}^{2}+2\left(n^{2}-2 n-3\right) \theta_{2}-3(n+1)^{2}\right] \frac{R^{2}}{16 b(n+1)^{2}\left(\theta_{2}+1\right)^{2}}
$$

a) when $n=1$,

$\pi_{s c}^{*}-\pi_{s c}^{* * *}=-4\left(2 \theta_{2}+3\right) \frac{R^{2}}{16 b(n+1)^{2}\left(\theta_{2}+1\right)^{2}}<0$, then $\pi_{s c}^{*}<\pi_{s c}^{* * *}$

b) when $n>1$,

$f\left(\theta_{2}\right)=\left(n^{2}+2 n-3\right) \theta_{2}^{2}+2\left(n^{2}-2 n-3\right) \theta_{2}-3(n+1)^{2}$ is a concave parabolic curve with the vertex Y-coordinate

$-3(n+1)^{2}-\frac{\left(2 n^{2}-4 n-6\right)^{2}}{4(n+3)(n-1)}<0$.

Since $f(0)=-3(n+1)^{2}<0, \quad f(1)=-8 n-12<0$, it can be induced that $f\left(\theta_{2}\right)<0,0 \leq \theta_{2} \leq 1$

And from $f(0)=-3(n+1)^{2}<0$, so

$f(1)=-8 n-12<0, \quad f\left(\theta_{2}\right)<0,0 \leq \theta_{2} \leq 1$

And $\pi_{s c}^{*}-\pi_{s c}^{* *}<0$, which means

$$
\pi_{s c}^{*}<\pi_{s c}^{* * *}=\pi^{* * * *}
$$

Since $\pi_{s c}^{* * * *}-\pi_{s c}^{* *}=(1-n)(3+n) \frac{R^{2}}{16 b} \leq 0$, so

$$
\pi_{s c}^{* * * *} \leq \pi_{s c}^{* *}
$$

That is, $\pi_{s c}^{* *}-\pi_{s c}^{* * * *}=-1<0$, so

$$
\pi_{s c}^{* *}<\pi_{s c}^{* * * *}
$$

Combine Function (1), (2) and (3), it can be concluded that,

$$
\pi_{s c}^{*}<\pi_{s c}^{* * *}=\pi_{s c}^{* * *} \leq \pi_{s c}^{* *}<\pi_{s c}^{* * * * *}
$$

Conclusion 3 shows that, in the large scale alliance case, all parties enhance supply chain's profit through reducing retail price and increasing sales. Therefore, in this case, not only all supply chain members maximize their profits but also customers are well off. However, partial cooperation can be a compromise if evitable obstacles exist in the process of all-round cooperation. Moreover, among the types of partial cooperation, supply chain's profit is maximized in the manufacturer-TPL case, which tell us that the retailer's competition can make customers, TPL and the manufacturer well off.

\section{Revenue Distribution under Joint Decision Making}

From the above analysis, it is clear that large scale alliance can bring about greatest profit. However, revenue conflict will lead to inefficient cooperation, the supply chain can only be coordinated through reasonable fair distribution of revenue.
Suppose that the revenue distributing coefficients of manufacturer, TPL provider and retailer are respectively $k_{m}, k_{l}, k_{r}$, and $k_{m}+k_{l}+k_{r}=1$. Only when each party's profit of a large scale alliance is bigger than that of the small scale alliance and even no alliance, supply chain members have the motive to participate in a large scale alliance.

\subsection{Revenue Distribution Based on Nash Bargaining Model}

Take each party's revenue (no alliance situation) as the bargaining points, i.e., $\pi_{m}^{*}, \pi_{l}^{*}, \pi_{r}^{*}$ are bargaining points, establish a bargaining model to solve each's revenue after cooperation based on Nash bargaining model.

$$
\begin{gathered}
\max Z=\left(k_{m} \pi_{s c}^{* * * * *}-\pi_{m}^{*}\right)\left(k_{l} \pi_{s c}^{* * * * *}-\pi_{l}^{*}\right)\left(k_{r} \pi_{s c}^{* * * * *}-\pi_{r}^{*}\right) \\
\text { s.t. } k_{m} \pi_{s c}^{* * * * *} \geq \pi_{m}^{*}, \quad k_{l} \pi_{s c}^{* * * * *} \geq \pi_{l}^{*}, \quad k_{r} \pi_{s c}^{* * * * *} \geq \pi_{r}^{*} \\
\left(k_{m}+k_{l}\right) \pi_{s c}^{* * * * *} \geq\left(\pi_{m}+\pi_{l}\right)^{* *} \\
\left(k_{l}+k_{r}\right) \pi_{s c}^{* * * * *} \geq\left(\pi_{l}+\pi_{r}\right)^{* * *} \\
\left(k_{m}+k_{r}\right) \pi_{s c}^{* * * * *} \geq\left(\pi_{m}+\pi_{r}\right)^{* * * *} \\
k_{m}+k_{l}+k_{r}=1
\end{gathered}
$$

\subsection{Revenue Distribution Based on Minimum Core Method}

According to minimum core method, a linear planning model is set up as follows:

$\min \varepsilon$,

$$
\begin{aligned}
\text { s.t. } \quad k_{m} \pi_{s c}^{* * * * *} \geq \pi_{m}^{*}, \quad k_{l} \pi_{s c}^{* * * *} \geq \pi_{l}^{*}, \quad k_{r} \pi_{s c}^{* * * * *} \geq \pi_{r}^{*} \\
\left(k_{m}+k_{l}\right) \pi_{s c}^{* * * * *}+\varepsilon \geq\left(\pi_{m}+\pi_{l}\right)^{* *}, \\
\left(k_{l}+k_{r}\right) \pi_{s c}^{* * * * *}+\varepsilon \geq\left(\pi_{l}+\pi_{r}\right)^{* * *}, \\
\left(k_{m}+k_{r}\right) \pi_{s c}^{* * * * *}+\varepsilon \geq\left(\pi_{m}+\pi_{r}\right)^{* * * * *} \\
k_{m}+k_{l}+k_{r}=1
\end{aligned}
$$

\subsection{Revenue Distribution Based on Simplified MCRS Method}

According to simplified MCRS Method, the linear function group is set up as follows:

$$
\left\{\begin{array}{l}
\pi_{j}=\pi_{j \min }+\lambda\left(\pi_{j \max }-\pi_{j \min }\right), j=m, l, r \\
\sum_{j=1}^{n} \pi_{j}=\pi_{s c}^{* * * *}
\end{array}\right.
$$


And, $\pi_{j \max }, \pi_{j \min }$ are defined as:

$$
\left\{\begin{array}{l}
\pi_{m \text { max }}=\pi_{s c}^{* * * * *}-\left(\pi_{l}+\pi_{r}\right)^{* * *}, \\
\pi_{l \text { max }}=\pi_{s c}^{* * * * *}-\left(\pi_{m}+\pi_{r}\right)^{* * * *}, \\
\pi_{r \text { max }}=\pi_{s c}^{* * * * *}-\left(\pi_{m}+\pi_{l}\right)^{* *}, \\
\pi_{m \text { min }}=\pi_{m}^{*}, \pi_{l \text { min }}=\pi_{l}^{*}, \pi_{r \text { min }}=\pi_{r}^{*}
\end{array}\right.
$$

\section{Numerical Analysis}

Utilizing some data from reference 4 and 6 , the parameters' value are set as follows: $a=30, b=0.2, c_{m}=5$, $c_{l}=2, c_{r}=3, \theta_{2}=0.8$.

1) $\theta_{2}$ 's influence on order quantity, all parties' pricing decisions and profits.

When $n=3$ :

From Figure 1, it's clear that along with the increase of $\theta_{2}$, the wholesale price, logistics service price and retail price decrease while the order quantity increases, and the increase rate of $Q$ is bigger than the decrease rate of $p_{i}$.

And from Figure 2, when $\theta_{2}$ increases, all parties' profits as well as the whole supply chain's profit increase. They reach the peak when $\theta_{2}=1$.

2) $n$ 's influence on order quantity, all parties' pricing decisions and profits.
From Table 1, in the decentralized model and small scale alliance situation, the order quantities increase with the increase of $n$, and when retailer is included into the alliance, i.e., the large scale alliance situation, the value of $n$ has no effect on order quantities.

From Table 2, in the decentralized model and small scale alliance situation, the retail prices increase with the increase of $n$, and when retailer is included into the alliance, i.e., the large scale alliance situation, the value of $n$ has no effect on retail prices.

From Table 3, in the decentralized model and small scale alliance situation, the total profits of the supply chain increase with the increase of $n$, and when retailer is included into the alliance, i.e., the large scale alliance situation, the value of $n$ has no effect on total supply chain profits. And in the decentralized model, the profits of manufacture and TPL provider increase with the increase of $n$, and the retailer's profit is just opposite. Therefore, the manufacturer can increase the whole supply chain's profit and his own profit by increasing the number of retailers, but he should consider some bad effects such as retailers' joint boycotts.

3) the comparison of order quantity, retail price and sales volume and profit under three circumstances.

From the three above tables, it can be concluded that in decentralized model, the order quantity was minimized,

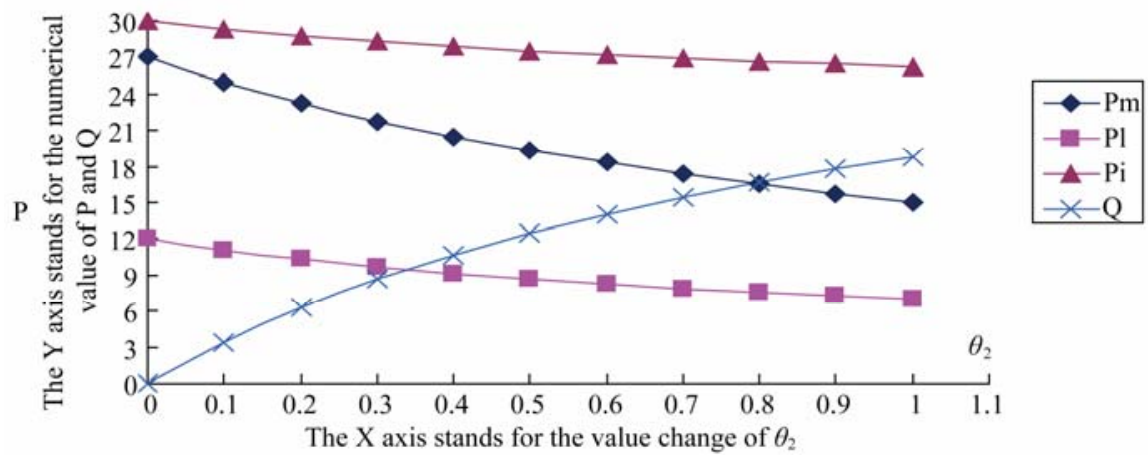

Figure 1. $\theta_{2}$ 's influence on order quantity, all parties' pricing decisions.

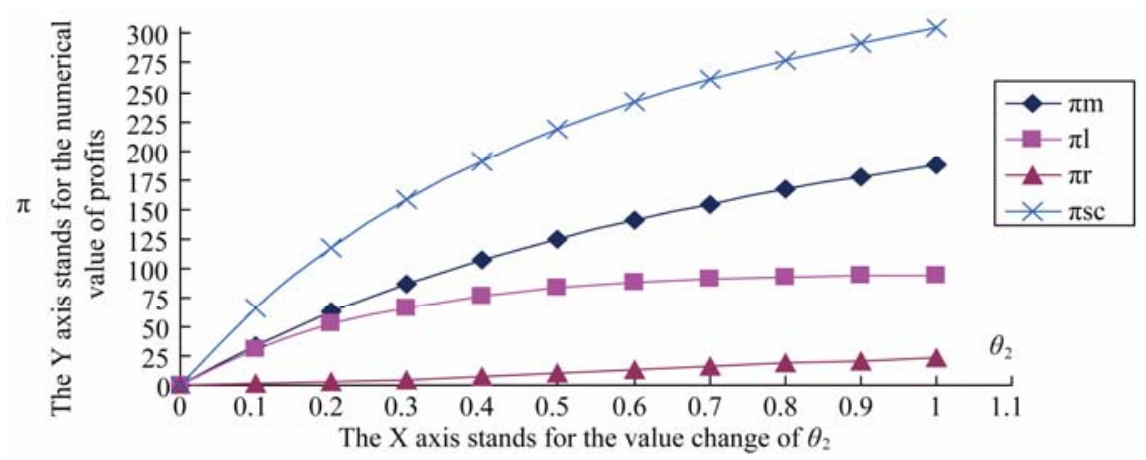

Figure 2. $\theta_{2}$ 's influence on all parties' profits and total supply chain profit. 
Table 1. Order quantities in all situations.

\begin{tabular}{cccccc}
\hline & Decentralized decision & \multicolumn{2}{c}{ Small scale alliance } & \multicolumn{2}{c}{ Large scale alliance } \\
\hline $\mathrm{n}=1$ & $\mathrm{Q}^{*}$ & $\mathrm{Q}^{* *}$ & $\mathrm{Q}^{* * *}$ & $\mathrm{Q}^{* * * *}$ & $\mathrm{Q}^{* * * *}$ \\
$\mathrm{n}=2$ & 11.111 & 25.000 & 25.000 & 25.000 & 50.000 \\
$\mathrm{n}=3$ & 14.815 & 33.333 & 25.000 & 25.000 & 50.000 \\
$\mathrm{n}=4$ & 16.667 & 37.500 & 25.000 & 25.000 & 50.000 \\
$\mathrm{n}=5$ & 17.778 & 40.000 & 25.000 & 25.000 & 50.000 \\
\hline
\end{tabular}

Table 2. Retail prices of all situations.

\begin{tabular}{cccccc}
\hline & Decentralized decision & \multicolumn{2}{c}{ Small scale alliance } & \multicolumn{2}{c}{ Large scale alliance } \\
\hline $\mathrm{n}=1$ & $\mathrm{p}_{\mathrm{i}}^{*}$ & $\mathrm{p}_{\mathrm{i}}^{* *}$ & $\mathrm{p}_{\mathrm{i}}^{* * *}$ & $\mathrm{p}_{\mathrm{i}}^{* * * *}$ & $\mathrm{p}_{\mathrm{i}}^{* * * *}$ \\
$\mathrm{n}=2$ & 27.778 & 25.000 & 25.000 & 25.000 & 20.000 \\
$\mathrm{n}=3$ & 27.037 & 23.333 & 25.000 & 25.000 & 20.000 \\
$\mathrm{n}=4$ & 22.500 & 25.000 & 25.000 & 20.000 \\
$\mathrm{n}=5$ & 26.667 & 22.000 & 25.000 & 25.000 & 20.000 \\
\hline
\end{tabular}

Table 3. Supply chain member' profits and total profits of all situations.

\begin{tabular}{|c|c|c|c|c|c|c|c|c|}
\hline & \multicolumn{4}{|c|}{ Decentralized decision } & \multicolumn{3}{|c|}{ Small scale alliance } & \multirow{2}{*}{$\begin{array}{c}\text { Large scale } \\
\text { alliance } \\
\pi_{\mathrm{sc}}^{* * * * *}\end{array}$} \\
\hline & $\pi_{\mathrm{m}}{ }^{*}$ & $\pi_{1}^{*}$ & $\pi_{\mathrm{r}}^{*}$ & $\pi_{\mathrm{sc}}^{*}$ & $\pi_{\mathrm{sc}}{ }^{* *}$ & $\pi_{\mathrm{sc}}{ }^{* * *}$ & $\pi_{\mathrm{sc}}{ }^{* * * *}$ & \\
\hline $\mathrm{n}=1$ & 111.111 & 61.728 & 24.691 & 197.531 & 375.000 & 375.000 & 375.000 & 500.000 \\
\hline $\mathrm{n}=2$ & 148.148 & 82.305 & 21.948 & 252.401 & 444.444 & 375.000 & 375.000 & 500.000 \\
\hline $\mathrm{n}=3$ & 166.667 & 92.593 & 18.519 & 277.778 & 468.75 & 375.000 & 375.000 & 500.000 \\
\hline $\mathrm{n}=4$ & 177.778 & 98.765 & 15.802 & 292.346 & 480.000 & 375.000 & 375.000 & 500.000 \\
\hline $\mathrm{n}=5$ & 185.185 & 102.881 & 13.717 & 301.783 & 486.111 & 375.000 & 375.000 & 500.000 \\
\hline
\end{tabular}

the retail price was the highest and the total profit was the lowest, while in large scale alliance case they are totally opposite. And in the small scale alliance case, the total profit maximized when the manufacturer and TPL provider form the alliance.

Use Excel and Lingo to calculate the profits of all parties and their growth rates under different revenue distribution method, the results are shown in Tables $\mathbf{4}$ and $\mathbf{5}$.

It is clear that in this numerical case, when adopting the Minimum core method, the TPL provider gains all the extra profit of the system, i.e., the manufacturer and retailer's profits are not improved. Therefore, this method cannot be used to distribute profits, but it can be a basis for the three parties to negotiate. Each party's profit is improved greatly though the growth extent is not the same when adopting Nash bargaining model and Simplified MCRS method. The manufacturer and TPL provider's profits are maximized under the simplified MCRS method while the retailer's profit is maximized under Nash bargaining model, which means when the three begin to negotiate they prefer different revenue distribution methods. Since here is the supply chain situation led by the manufacturer, which means he has the strongest bargaining power, so the simplified MCRS method will be used by the alliance. Besides that, the growth extent of retailer's profit under this method is greater than under the other two methods, so in this case, the simplified MCRS method is the ideal one. The distributing coeffi- 
Table 4. All parties’ profits under different revenue distribution method.

\begin{tabular}{cccc}
\hline & Nash bargaining model & Minimum core method & Simplified MCRS Method \\
\hline Manufacturer & 240.741 & 166.667 & 244.186 \\
TPL provider & 166.667 & 314.814 & 197.674 \\
retailer & 92.592 & 18.519 & 58.140 \\
\hline
\end{tabular}

Table 5. Growth rates under different distribution method.

\begin{tabular}{|c|c|c|c|c|}
\hline & & Nash bargaining model & Minimum core method & Simplified MCRS method \\
\hline \multirow{3}{*}{$\begin{array}{l}\text { Decentralized } \\
\text { model }\end{array}$} & manufacturer & $44.44 \%$ & $0.00 \%$ & $46.51 \%$ \\
\hline & TPL provider & $80.00 \%$ & $240.00 \%$ & $113.49 \%$ \\
\hline & retailer & $399.98 \%$ & $0.00 \%$ & $213.95 \%$ \\
\hline \multirow{3}{*}{$\begin{array}{l}\text { Small scale } \\
\text { alliance }\end{array}$} & $M+L$ & $8.64 \%$ & $28.39 \%$ & $17.83 \%$ \\
\hline & $\mathrm{L}+\mathrm{R}$ & $107.41 \%$ & $166.67 \%$ & $104.65 \%$ \\
\hline & $M+R$ & $166.67 \%$ & $48.15 \%$ & $141.86 \%$ \\
\hline
\end{tabular}

cients are separately $0.488,0.396,0.116$.

\section{Conclusions}

Based on the above analysis of wholesale price contract, the supply chain coordination problem with TPL participation was discussed associated with revenue sharing and distribution theory. The following conclusions are obtained:

1) In the decentralized model, Pareto improvement can be realized through reasonable distribution of the logistics fee between the retailer and manufacturer; as the supply chain leader, the manufacturer has to choose a certain number of retailers to balance their profits.

2) In the three types of small scale alliances, the total supply chain profit is the greatest when the manufacturer and the TPL provider form a alliance.

3) All node enterprise's profits are maximized in the large scale alliance, and minimized in the decentralized model.

4) Supply chain firms can choose an appropriate revenue distribution method, such as Nash bargaining model, minimum core method and simplified MCRS method to coordinate the supply chain.

\section{REFERENCES}

[1] A. Vining and S. Globerman, "A Conceptual Framework for Understanding the Outsourcing Decision," European Management Journal, Vol. 17, No. 6, 1999, pp. 183-198.

[2] D. L. Yang and Y. Jiang, "Quantitative Research on the Collaboration between Node Enterprise and Third Party Logistics under SCM," China Soft Science, Vol. 3, 2002, pp. 1-5.

[3] Y. Y. Zheng, "Study on the Cooperation Relationship between Third Party Logistics and Vendor under Supply Chain," Qing Dao University, 2005.

[4] S. Huang and B. Y. Li, "The Coordination of the Third Party Logistics Based on Revenue Sharing," Businuess Economies, Vol. 11, 2008, pp. 5-8.

[5] B. Dan, Q. Wu, X. M. Zhang and J. Xiao, "Shared-Savings Contracts between a Third Party Logistics Service Provider and a Client Enterprise," System Engineering-Theory and Practice, Vol. 2, 2007, pp. 46-53.

[6] Y. D. Gong, B. Y. Li and T. Liu, "The Pricing and Coordination Policies of Three-Echelon Supply Chain," Price Monthly, Vol. 9, 2008, pp. 12-14.

[7] F. Ye and Y. N. Li, "The Motivation Mechanism of Three- echelon Supply Chain Cooperation," Journal of System Management, Vol. 16, No. 2, 2007, pp. 130-134. 